\title{
Effects of Tianxiangdan Granule treatment on atherosclerosis via NF- $\kappa B$ and p38 MAPK signaling pathways
}

\author{
LONG-FEI SUN ${ }^{1,2}$, DONG-QING AN ${ }^{2,3}$, GU-LIJIAMALI NIYAZI ${ }^{4}$, \\ WEN-HUI MA ${ }^{2}$, ZHENG-WEI XU ${ }^{2}$ and YANG XIE ${ }^{2}$ \\ ${ }^{1}$ Coronary Care Unit, Affiliated Hospital of Traditional Chinese Medicine, Xinjiang Medical University, Urumqi, \\ Xinjiang 830000; ${ }^{2}$ Department of Traditional Chinese Medicine, College of Traditional Chinese Medicine, \\ Xinjiang Medical University; ${ }^{3}$ Xinjiang Key Laboratory of Famous Prescription and Science of Formulas, \\ Urumqi, Xinjiang 830011; ${ }^{4}$ Rehabilitation Unit, Affiliated Hospital of Traditional Chinese Medicine, \\ Xinjiang Medical University, Urumqi, Xinjiang 830000, P.R. China
}

Received June 3, 2016; Accepted April 7, 2017

DOI: $10.3892 / \mathrm{mmr} .2017 .8067$

\begin{abstract}
The present study aimed to determine the effects of Tianxiangdan Granule on nuclear factor (NF)-кB p65 and p38 mitogen-activated protein kinase (MAPK) inflammatory signaling pathways, and explored the possible mechanism underlying the effects of Tianxiangdan Granule on prevention and treatment of atherosclerosis. A total of 48 apolipoprotein $\mathrm{E}^{-/-}$mice (age, 8 weeks) were selected and divided into two groups: The normal control group $(n=12)$ and the modeling group $(n=36)$. In the modeling group, mice were fed a high-fat diet and were maintained in an artificial climate box, in order to stimulate the climate and eating habit characteristics of Xinjiang. Every morning, ApoE-/- mice in the modeling group were placed in the artificial climate box at 10:00 am and were taken out at 09:00 pm and placed back in the room temperature environment. The temperature of the artificial climate box was set at $6 \pm 2^{\circ} \mathrm{C}$, relative humidity was controlled at $25-32.8 \%$ and the light-dark cycle was $12 \mathrm{~h} /$ day. The purpose of this method was to establish the Huizhuo Tanzu type atherosclerosis model. Following successful generation of the model, mice in the modeling group were randomly divided into three groups: Model group $(n=10)$, Tianxiangdan group $(n=10)$ and atorvastatin group $(n=10)$. After 12 weeks, mice were sacrificed and the serum levels of interleukin (IL)- $1 \beta$ and tumor necrosis factor (TNF)- $\alpha$ in each group were detected. Furthermore, the expression levels of NF- $\kappa$ B p65 and p38 MAPK in aortic tissue were detected. The results indicated that the concentrations of IL-1 $\beta$ and TNF- $\alpha$ were significantly higher in mice in
\end{abstract}

Correspondence to: Dr Dong-Qing An, Department of Traditional Chinese Medicine, College of Traditional Chinese Medicine, Xinjiang Medical University, 393 Xinyi Street, Xinshi, Urumqi, Xinjiang 830011, P.R. China

E-mail: dongqingandoc@163.com

Key words: Tianxiangdan Granule, inflammatory factors, nuclear factor- $\kappa \mathrm{B}$ p65, p38 mitogen-activated protein kinase, atherosclerosis the model group compared with in the normal control group $(\mathrm{P}<0.01)$, whereas the concentrations of IL-1 $\beta$ and TNF- $\alpha$ were lower in the Tianxiangdan and atorvastatin groups compared with in the model group $(\mathrm{P}<0.01)$. Furthermore, the protein expression levels of phosphorylated (p)-NF- $\mathrm{B}$ p65 and p-p38 MAPK protein were higher in aortic tissues from the model group compared with in the normal control group $(\mathrm{P}<0.01), \mathrm{p}-\mathrm{NF}-\kappa \mathrm{B}$ p65 and p-p38 MAPK protein expression was reduced in the atorvastatin and Tianxiangdan groups compared with in the model group. The present study indicated that the mechanism underlying the effects of Tianxiangdan Granule on the prevention and treatment of atherosclerosis may be as follows: Tianxiangdan Granule may decrease the expression of the inflammatory cytokines IL- $1 \beta$ and TNF- $\alpha$, and suppress activation of the NF- $\mathrm{B}$ p 65 and p38 MAPK signaling pathways.

\section{Introduction}

Atherosclerosis (AS) is the pathological basis of cardiovascular diseases, and is an important cause of cardiovascular disease-associated mortality $(1,2)$. The Report on Cardiovascular Disease in China (2014) revealed that the prevalence of cardiovascular diseases in China continues to rise; in 2014 , there were $\sim 0.29$ billion patients with cardiovascular disease in China, and one in every five adults was reported to suffer from a cardiovascular disease (3). Therefore, the effective prevention and treatment of AS is of great significance to prevent the occurrence of cardiovascular diseases. The pathogenesis of AS has been explained by numerous theories, including the lipid infiltration theory, the endothelial damage theory, the inflammatory reaction theory and the oxidative stress theory $(4,5)$. During the occurrence and development of AS, various inflammatory cells and inflammatory mediators serve roles in the formation and rupture of fatty streaks, as well as fibrous, atheromatous and unstable plaques (6). In 1999, Ross proposed the concept that AS is a chronic inflammatory disease (7). Nuclear factor (NF)- $\kappa \mathrm{B}$ and mitogen-activated protein kinase (MAPK) signaling pathways may be involved in the formation of AS via the regulation of inflammatory 
cytokine-mediated inflammation. Therefore, prevention and treatment of AS via the regulation of inflammatory signaling pathways may be considered a novel strategy to control the inflammatory reaction, and effectively delay plaque formation or prevent plaque rupture by stabilizing plaques.

Tianxiangdan Granule was developed by Professor Dongqing An, a doctor in the field of traditional Chinese medicine. Tianxiangdan Granule was developed according to the special geographical features and climate of Xinjiang, China, as well as the diet and lifestyle of the local residents. Tianxiangdan Granule is composed of Rhodiola, Ziziphora clinopodioides, Dalbergia and Salvia miltiorrhiza. It has been used in the clinical prevention and treatment of AS-associated diseases for $>30$ years, with good clinical effects. Previous studies have revealed that Tianxiangdan Granule exerts the following effects: Regulation of lipid metabolism, improving endothelial function and energy metabolism of ischemic myocardia, reducing myocardial cell damage and reducing oxidative stress (8-11). At present, few studies have been performed regarding the association between the effects of Tianxiangdan Granule on the prevention and treatment of AS, and inflammatory factors and related signaling pathways; therefore, the present study was conducted. On the basis of the successful replication of the apolipoprotein $\mathrm{E}(\mathrm{ApoE})^{-/-}$murine model of Huizhuo Tanzu type AS, the present study investigated the effects of Tianxiangdan Granule on inflammatory factors and inflammatory signaling pathways, in order to explore the possible anti-AS mechanism underlying the effects of Tianxiangdan Granule.

\section{Materials and methods}

Animals. A total of $48 \mathrm{ApoE}^{-/-}$mice [strain C57BL/6J] in the present study were introduced from the Jackson laboratory in the United States by the Peking University Medical Laboratory Animal Center. The mice were purchased as ApoE-/-. All mice [male; age, 8 weeks; weight, $18 \pm 2 \mathrm{~g}$; license no. SCXK (Beijing) 2011-0012] were maintained in the Medical Animal Experimental Center of The First Affiliated Hospital of Xinjiang Medical University (Urumqi, China). They were fed normal diet at room temperature (relative humidity: 40-70\%, $12 \mathrm{~h} / \mathrm{d}$ light dark cycle). The present study was approved by the Animal Ethics Committee of The First Affiliated Hospital of Xinjiang Medical University.

Drugs and reagents. Tianxiangdan Granule is composed of four types of Chinese medicine: Rhodiola root, Dalbergia wood, Ziziphora clinopodioides and Salvia miltiorrhiza. The drug was prepared by the Traditional Chinese Medicine Hospital Affiliated to Xinjiang Medical University (batch no. ZO4000820). Tianxiangdan Granule obtained a national patent in 2009 (patent no. 200910210063.9) (12). Atorvastatin calcium tablets (batch no. H20051408) were purchased from Pfizer Inc. (New York, NY, USA). Cholesterol was obtained from Amresco, LLC (Solon, OH, USA). Propylthiouracil tablets were purchased from Riemser Pharma $\mathrm{GmbH}$ (Greifswald, Germany). TNF- $\alpha$ (cat. no. 106958008) and IL-1 $\beta$ (cat. no. 92572000) ELISA kits were purchased from eBioscience; Thermo Fisher Scientific, Inc. (Waltham, MA, USA). Radioimmunoprecipitation assay (RIPA) buffer, Pierce
Phosphatase Inhibitor Mini Tablets, Halt Protease Inhibitor Cocktail and bicinchoninic acid (BCA) Protein Assay kit were obtained from Thermo Fisher Scientific, Inc. Triglyceride (TG) assay kit (cat. no. A110-2), total cholesterol (TC) assay kit (cat. no. A111-2), low-density lipoprotein cholesterol (LDL-C) assay kit (cat. no. A113-2) and high-density lipoprotein cholesterol (HDL-C) assay kit (cat. no. A112-2) were purchased from Nanjing Jiancheng Bioengineering Institute (Nanjing, China). The following primary antibodies were purchased from Cell Signaling Technology, Inc. (Danvers, MA, USA): Phosphorylated (p)-p38 MAPK (cat. no. 4631S), p38 MAPK

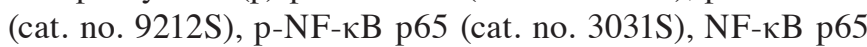
(cat. no. 8242S) and GAPDH (cat. no. 5174S). Alkaline phosphatase-conjugated secondary antibody (Anti-Rabbit) (cat. no. WP0007) and BCIP/NBT Chromogenic Substrate were purchased from Invitrogen (Thermo Fisher Scientific, Inc.). Polyvinylidene fluoride (PVDF) membrane was obtained from Roche Diagnostics (Basel, Switzerland).

Establishment of the animal model. Of the 48 8-week-old $\mathrm{ApoE}^{-/-}$mice, 12 were assigned to the normal control group, in which mice were provided ordinary diets, and were maintained at room temperature $\left(20-24^{\circ} \mathrm{C}\right)$ and $40-70 \%$ relative humidity. The remaining $36 \mathrm{ApoE}^{-/-}$mice were assigned to the modeling group, in which mice were fed a high-fat diet and were maintained in an artificial climate box, in order to stimulate the climate and eating habit characteristics of Xinjiang. Every morning, ApoE ${ }^{-/-}$mice in the modeling group were placed in the artificial climate box at 10:00 a.m. and were taken out at 09:00 p.m. when they were placed back in the room temperature environment. The temperature of the artificial climate box was set at $6 \pm 2^{\circ} \mathrm{C}$, relative humidity was controlled between 25 and $32.8 \%$, and the light-dark cycle was $12 \mathrm{~h} /$ day. The purpose of this method was to establish the Huizhuo Tanzu type AS model $(13,14)$. After 12 weeks of feeding, $2 \mathrm{ApoE}^{-/-}$mice from the normal control group and $6 \mathrm{ApoE}^{-/-}$mice from the modeling group were randomly selected and sacrificed, after which, aortic roots were obtained and observed under a light microscope following hematoxylin and eosin (H\&E) staining. In samples from the modeling group, an increased number of foam cells, cholesterol crystals and atheromatous plaques were observed, and lumen stenosis was clearly demonstrated. In addition, the remaining $\mathrm{ApoE}^{-/-}$mice in the modeling group appeared lethargic, their participation in activities was decreased, food and water intake was reduced, their fur appeared lackluster, weight growth was not obvious, and they had sticky stools. These signs confirmed that the Huizhuo Tanzu type AS model had been successfully established. Furthermore, the remaining $30 \mathrm{ApoE}^{-/-}$mice were randomly divided into three groups: Model group, Tianxiangdan group $\left[2.7 \mathrm{~g} \cdot(\mathrm{kg} \cdot \mathrm{d})^{-1}\right]$, and atorvastatin group $\left[6.1 \mathrm{mg}(\mathrm{kg} \cdot \mathrm{d})^{-1}\right] ; \mathrm{n}=10 \mathrm{mice} /$ group. The aforementioned doses were selected by equivalent conversion, based on the clinical routine dose used to treat human adults: Mouse experimental dose $\left[\mathrm{g}(\mathrm{kg} \cdot \mathrm{d})^{-1}\right]=9.1 \mathrm{x}$ human adult clinical dose $\left[\mathrm{g} \cdot(\mathrm{kg} \cdot \mathrm{d})^{-1}\right]$. To obtain the experimental doses, drugs were dissolved in distilled water and administered by gavage once a day (15). Doses were adjusted according to body weight each week. Mice in the normal control and model groups were administered an oral gavage of distilled water $\left(0.2 \mathrm{ml} \cdot \mathrm{d}^{-1}\right)$. All mice were given free access to food and water, 
and their activities were not restricted. Mice in the normal control group were placed at room temperature $\left(20-24^{\circ} \mathrm{C}\right)$ and $40-70 \%$ relative humidity, and were given a normal diet. Mice in the model, Tianxiangdan and atorvastatin groups were administered a high-fat diet and continued to undergo intermittent maintenance in the artificial climate box. The high-fat diet comprised: Basal diet, $72.5 \%$; lard, 10\%; sucrose, $10 \%$; pig bile salt, $0.2 \%$; cholesterol, $2 \%$; propylthiouracil, $0.12 \%$; egg yolk, 5\%; and 21 Super-Vita, $0.1 \%$. The temperature of the artificial climate box was set at $6 \pm 2{ }^{\circ} \mathrm{C}$, and relative humidity was controlled between 25 and $32.8 \%$.

Experimental specimen collection. A total of 12 weeks following administration of the first gavage, $\mathrm{ApoE}^{-/-}$mice in all groups were fasted. After $12 \mathrm{~h}$ the following operations were conducted: i) Mice were anesthetized by $0.1 \mathrm{ml} / \mathrm{kg}$ intraperitoneal injection of anaesthetic composed of $2 \mathrm{ml}$

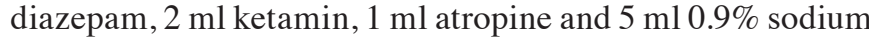
chloride, and blood samples were collected from the eyeballs. The samples were placed in microcentrifuge tubes and were centrifuged at $3,000 \times \mathrm{g}$ for $10 \mathrm{~min}$ at $4^{\circ} \mathrm{C}$; the serum obtained by separation was maintained at $-80^{\circ} \mathrm{C}$ for the detection of serological markers. Repeated freezing and thawing was avoided. ii) Mice were anesthetized by $0.1 \mathrm{ml} / \mathrm{kg}$ intraperitoneal injection of anesthetic (injection of diazepam, ketamine and atropine), then were sacrificed by cervical dislocation. Thoraces and abdomens were opened; arterial tissues from the aortic root to the branches between the iliac and renal artery were obtained and rinsed in normal saline. A length of $\sim 0.5 \mathrm{~cm}$ from the aortic root was obtained, and fixed in $10 \%$ formalin for H\&E staining and plaque area (PA) analysis. Residual aortic tissues were quickly placed in microcentrifuge tubes, labeled, and placed into liquid nitrogen and quickly frozen. The samples were then transferred into an ultra-low temperature freezer at $-80^{\circ} \mathrm{C}$, and preserved for detection by western blotting.

$H \&$ E staining PA analysis. Aorta tissues were fixed at $56^{\circ} \mathrm{C}$ for $12 \mathrm{~h}$ with $10 \%$ formaldehyde and dehydrated, prior to conventional paraffin embedding and dyeing with hematoxylin and eosin. From the aortic root, uniform slices were obtained $(\sim 5 \mu \mathrm{m}) ; 40$ consecutive slices were obtained from each sample. One slice was obtained from every five slices; therefore, a total of eight slices were obtained from each sample. After H\&E staining, aortic morphological alterations were observed under a light microscope; measurement and analysis of relevant pathological morphological indices were conducted using the multifunctional image analysis software of Image-Pro Plus (version 6.0; Media Cybernetics, Inc., Rockville, MD, USA). Blood vessel lumen area (LA) and PA measurements were obtained, and the PA/LA ratio was calculated. The mean values of PA/LA were calculated for statistical analysis.

Triglyceride (TG), total cholesterol (TC), high-density lipoprotein cholesterol (HDL-C) and low-density lipoprotein cholesterol (LDL-C) serum levels detected by enzymatic colorimetry. Prior to detection, serum samples were removed from the ultra low temperature freezer and were placed in a refrigerator at $4^{\circ} \mathrm{C}$. Subsequently, TG, TC, HDL-C and LDL-C serum levels were detected according to the manufacturer's protocols an automatic biochemical analyzer (cat. no. BS200; Mindray Medical International Co., Ltd., Shenzhen, China).

Serum expression levels of interleukin (IL)-1 $\beta$ and tumor necrosis factor (TNF)- $\alpha$ detected by ELISA method. Prior to detection, serum samples were removed from the ultra low temperature freezer and were placed in a refrigerator at $4^{\circ} \mathrm{C}$. Subsequently, the serum levels of proinflammatory cytokines IL-1 $\beta$ and TNF- $\alpha$ were detected using an ELISA kit, according to the manufacturer's protocol. Absorbance values were determined using an enzymatic microplate reader at a wavelength of $450 \mathrm{~nm}$. A standard curve was generated, with concentration as the horizontal coordinate and standard absorbance value as the vertical coordinate. The concentrations of IL- $1 \beta$ and TNF- $\alpha$ in the samples were calculated using the standard curve.

Expression levels of $N F-\kappa B$ p 65 and p38 MAPK signaling pathways detected by western blotting. Aortic tissue protein was extracted using RIPA with a protease inhibitor and phosphatase inhibitor, and protein concentration was determined using a BCA protein assay kit. Protein samples $(20 \mu \mathrm{g})$ were separated by $12 \%$ sodium dodecyl sulfate-polyacrylamide gel electrophoresis at $80 \mathrm{~V}$ and were transferred onto a PVDF membrane by electroblotting. The membrane was blocked in TBS-Tween 20 (TBST) supplemented with $5 \%$ w/v bovine serum albumin (Beijing Raghan Biological Technology Co. Ltd., Beijing, China) for $1 \mathrm{~h}$ at room temperature. Subsequently, the membrane was washed three times with TBST, and was incubated with the following primary antibodies: GAPDH

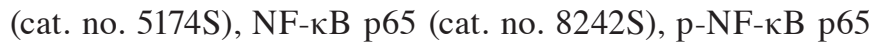
(cat. no. 3031S), p38 MAPK (cat. no. 9212S) and p-p38 MAPK (cat. no. 4631S) (all antibodies: 1:1,000 of dilution, Cell Signaling Technology, Inc.), at $4^{\circ} \mathrm{C}$ overnight with agitation. After washing the membrane with TBST three times, the alkaline phosphatase-conjugated secondary antibody (cat. no. WP0007) was added (1:1 of dilution; Thermo Fisher Scientific, Inc.), and the membrane was further incubated at $37^{\circ} \mathrm{C}$ for $1 \mathrm{~h}$. The membrane was then washed with TBST and underwent visualization in the dark with the BCIP/NBT Chromogenic Substrate. The blots were scanned and analyzed using Quantity One v4.62 software (Bio-Rad Laboratories, Inc., Hercules, CA, USA).

Statistical analysis. Statistical analysis was conducted using statistical software SPSS 17.0 (SPSS Inc., Chicago, IL, USA). Data were expressed as the mean \pm standard deviation of three independent experiments. Intergroup comparison was performed using one-way analysis of variance, and the comparison between two groups was performed using the Least Significant Difference method. $\mathrm{P}<0.05$ was considered to indicate a statistically significant difference.

\section{Results}

Physiological alterations of Huizhuo Tanzu type AS ApoE-/mice. Mice in the normal control group were lively, irritable and restless, had a quick response, bit each other frequently, ate a lot of food and drank a lot of water, gained significant amounts of weight, had clean and shiny fur, and had dry granular stools. 
Table I. Biological characteristics of apolipoprotein E-/- mice in the various groups.

\begin{tabular}{|c|c|c|c|c|}
\hline Characteristic & Normal control group & Model group & Atorvastatin group & Tianxiangdan group \\
\hline Tongue & Pink & $\begin{array}{l}\text { Bruising, with } \\
\text { ecchymosis }\end{array}$ & $\begin{array}{l}\text { Purple or dark red, } \\
\text { with ecchymosis }\end{array}$ & $\begin{array}{l}\text { Dark red, with } \\
\text { ecchymosis }\end{array}$ \\
\hline $\begin{array}{l}\text { Coating on } \\
\text { the tongue }\end{array}$ & Thin white coating & $\begin{array}{l}\text { Thick and greasy } \\
\text { coating }\end{array}$ & $\begin{array}{l}\text { Relatively thick and } \\
\text { greasy coating }\end{array}$ & $\begin{array}{l}\text { Thin and greasy } \\
\text { coating }\end{array}$ \\
\hline Fur & Clean and shiny & Dry and lackluster & Relatively dry and dull & $\begin{array}{l}\text { Relatively clean } \\
\text { and shiny }\end{array}$ \\
\hline Emotional state & Irritable and agitated & Docile & Docile & $\begin{array}{l}\text { Relatively irritable } \\
\text { and restless }\end{array}$ \\
\hline Behavioral state & Lively, fighting & $\begin{array}{l}\text { Reduced movement, } \\
\text { tired and sleepy }\end{array}$ & $\begin{array}{l}\text { Reduced movement, } \\
\text { tired and sleepy }\end{array}$ & $\begin{array}{l}\text { Relatively lively, } \\
\text { occasionally } \\
\text { biting/fighting }\end{array}$ \\
\hline Response to stimulus & Agile & Slow & Slow & Relatively agile \\
\hline Stool state & Dry, granular & Sticky & Slightly sticky & $\begin{array}{l}\text { Relatively dry, } \\
\text { granular }\end{array}$ \\
\hline Food intake & Normal & Significantly reduced & Reduced & Slightly reduced \\
\hline Water intake & Normal & Significantly reduced & Reduced & Slightly reduced \\
\hline Weight change & Significant growth & Growth not obvious & $\begin{array}{l}\text { Slightly increased } \\
\text { growth }\end{array}$ & $\begin{array}{l}\text { Slightly increased } \\
\text { growth }\end{array}$ \\
\hline
\end{tabular}

Mice in the model group became lethargic, their participation in activities significantly decreased, their food and water intake decreased, their fur was lackluster, weight growth was not obvious, and they had sticky stools. Characteristics of the mice in the Tianxiangdan and atorvastatin groups were better compared with those in the model group, their fur was relatively clean and shiny, and their water and food consumption, and weight gain, was larger than in the model group, and their stools were granular but slightly sticky (Table I).

Pathological alterations in the aorta of Huizhuo Tanzu type AS ApoE $E^{-/}$mice. In the normal control group, no obvious smooth muscle cell hyperplasia was detected, slight hyperplasia of the intima was observed, and no cholesterol crystal formation or obvious stenosis was detected in the aortic lumen (Fig. 1A). In the model group, numerous atherosclerotic plaque lesions appeared and the thickness of the aortic tube wall was obviously uneven. In addition, endothelial lesions had a larger PA and a thin fibrous cap. Large amounts of foam cells and cholesterol crystals were also detected, lipid cores were larger, and the majority of plaques did not closely adhere to the tube wall and some were detaching. Furthermore, calcification occurred locally, and considerable inflammatory cell infiltration was detected in the adventitia (Fig. 1B). In the Tianxiangdan group, atherosclerotic lesions were mainly fibrous plaque lesions, aortic tube wall thickness was uneven, the intima was markedly thicker, and fibrous plaques covered with a fibrous cap were clearly observed. The PA was markedly smaller than that in the model group. All plaques closely adhered to the aortic wall, and no detachment was observed. In addition, fibrous caps were thicker, lipid cores were small, and a small amount of inflammatory cell infiltration was detected in the adventitia (Fig. 1C). Pathological alterations were less severe than in the model group and plaque stability was improved, thus suggesting that Tianxiangdan increased plaque stability. In the atorvastatin group, the majority of alterations were detected in the atherosclerotic fibrous plaque lesions, the thickness of the aortic wall was uneven, the intima appeared markedly thicker, and fibrous plaques covered by a fibrous cap were observed. The PA was markedly smaller compared with in the model group, and the plaques did not closely adhere to the aortic wall; however, detachment was not observed. Lipid cores were not obvious, and adventitial inflammatory cell infiltration was rare (Fig. 1D). Pathological alterations were less severe than in the model group, thus indicating that atorvastatin could increase plaque stability.

Morphological alterations in aortic lumen stenosis of Huizhuo Tanzu type AS ApoE ${ }^{-/}$mice. The PA/LA ratio was compared among the groups; PA and LA were measured using Image-Pro Plus software (version 6.0). Compared with the normal control group, the aortic PA/LA ratio was significantly increased in the model group $(\mathrm{P}<0.01)$. Compared with in the model group, aortic PA/LA ratio was significantly decreased in the Tianxiangdan and atorvastatin groups $(\mathrm{P}<0.01)$. There was no statistically significant difference in aortic $\mathrm{PA} / \mathrm{LA}$ ratio between mice in the Tianxiangdan and atorvastatin groups (P>0.05; Fig. 2).

Alterations in the serum lipid levels of Huizhuo Tanzu type $A S A_{p o E^{-/}}$mice. The results indicated that compared with in the normal control group, TC, TG, LDL-C and HDL-C content was significantly higher in the model group $(\mathrm{P}<0.05)$. Compared with in the model group, TC and LDL-C serum content was significantly lower in the atorvastatin and Tianxiangdan groups $(\mathrm{P}<0.01)$. There was no statistically significant difference in serum lipid levels between mice in the Tianxiangdan and atorvastatin groups $(\mathrm{P}>0.05$; Table II). 
A Normal control B group

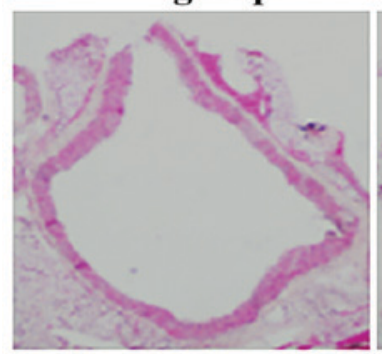

Model group

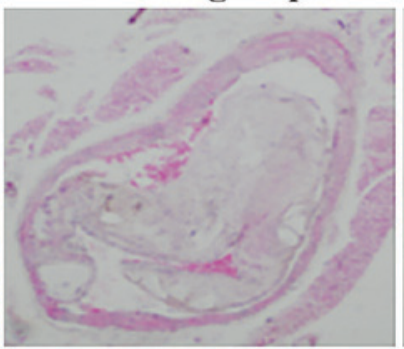

C Tianxiangdan group

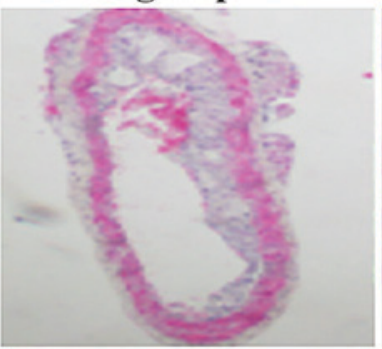

Tianxiangdan group
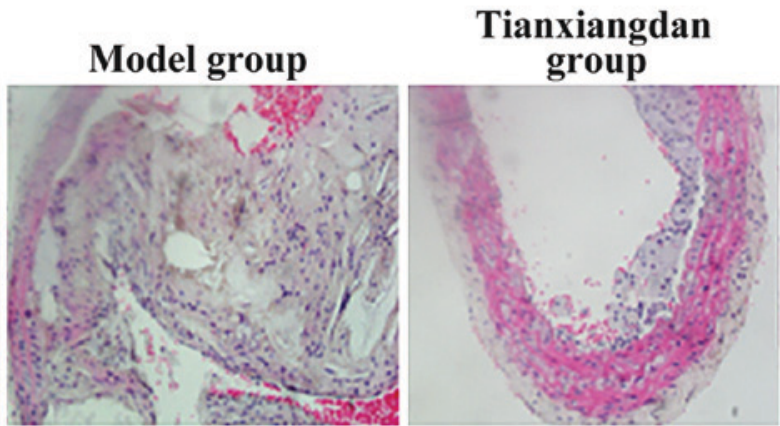

D Atorvastatin group

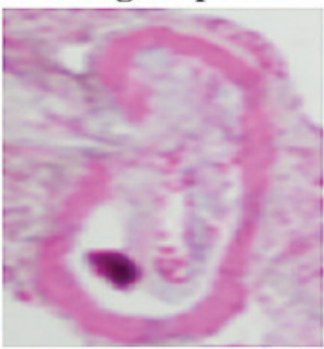

$(\times 100)$

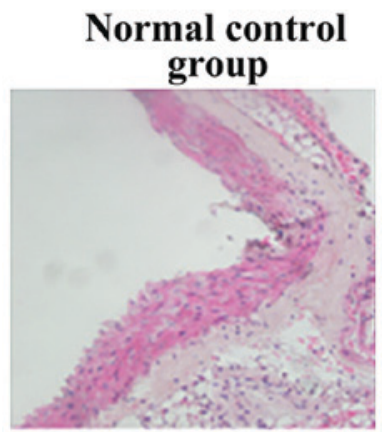

Atorvastatin group

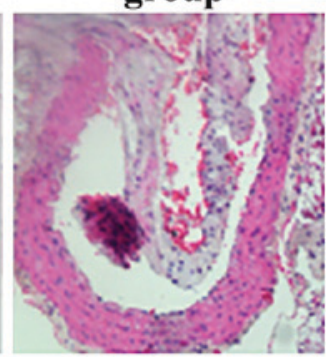

$(\times 400)$

Figure 1. Hematoxylin and eosin staining of aortic roots from apolipoprotein $\mathrm{E}^{-1}$ mice in the (A) normal control, (B) model, (C) Tianxiangdan and (D) atorvastatin groups (magnification, $\mathrm{x} 100$ and $\mathrm{x} 400$ ).

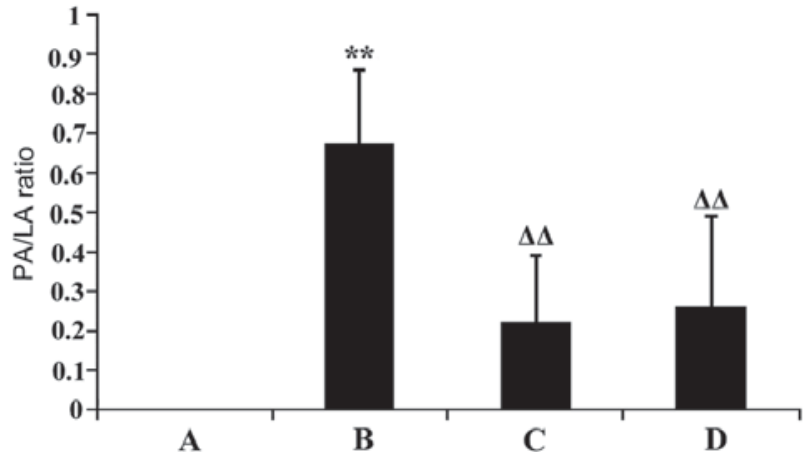

Figure 2. Comparison of the aortic root PA/LA ratio between the groups. $\mathrm{PA} / \mathrm{LA}$ ratio is presented by relative ratio. Data are expressed as the mean \pm standard deviation ( $\mathrm{n}=8$ apolipoprotein $\mathrm{E}^{-/-}$mice/group). A, normal control group; B, model group; C, Tianxiangdan group; $\mathrm{D}$, atorvastatin group. ${ }^{* *} \mathrm{P}<0.01$, compared with the normal control group; ${ }^{\Delta \Delta} \mathrm{P}<0.01$, compared with the model group. PA, plaque area; LA, lumen area.

Alterations in serum expression levels of $I L-1 \beta$ and TNF- $\alpha$ in Huizhuo Tanzu type AS ApoE $E^{-/}$mice. Compared with in the normal control group, serum IL-1 $\beta$ and TNF- $\alpha$ levels were significantly higher in the model group $(\mathrm{P}<0.01)$. Compared with in the model group, the serum levels of IL-1 $\beta$ and TNF- $\alpha$ were significantly lower in the Tianxiangdan and atorvastatin groups $(\mathrm{P}<0.01)$. There was no statistically significant difference in serum IL-1 $\beta$ and TNF- $\alpha$ levels between mice in the Tianxiangdan and atorvastatin groups ( $\mathrm{P}>0.05$; Table III).

Alterations in the expression levels of NF- $\kappa B$ p 65 and $p 38$ MAPK in aortic tissues of Huizhuo Tanzu type AS Apomice. Compared with the in normal control group, the protein expression levels of p-NF- $\kappa \mathrm{B}$ p65 and p-p38 MAPK were significantly increased in the aortic tissue of the model group $(\mathrm{P}<0.01)$. Compared with in the model group, the protein expression levels of $\mathrm{p}-\mathrm{NF}-\kappa \mathrm{B}$ p65 and $\mathrm{p} 38$ MAPK were significantly decreased in the Tianxiangdan and atorvastatin groups $(\mathrm{P}<0.01)$. There was no statistically significant difference in the protein expression levels of p-NF- $\mathrm{kB}$ p 65 and p-p38 MAPK between mice in the Tianxiangdan and atorvastatin groups ( $\mathrm{P}>0.05$; Figs. 3 and 4 ).

\section{Discussion}

AS is caused by complex pathological alterations, which are mediated by numerous factors. The pathogenesis of AS cannot be completely explained by one or two theories; however, it has been confirmed that the inflammatory response has a critical role in the occurrence and development of AS (16). Previous studies regarding signaling pathways and gene transcription levels have revealed that the cytokine-mediated inflammatory response is a key factor in the formation of AS; therefore, regulation of the inflammatory response may be important in the prevention and treatment of AS $(17,18)$. NF- $\mathrm{kB}$ was initially detected in B lymphocytes in 1986 by Sen and Baltimore (19). $\mathrm{NF}-\kappa \mathrm{B}$ is a homologous or heterologous dimer transcription factor formed from the Rel family of proteins, and is composed of two subunits, p50 and p65, which can specifically bind with the promoter or enhancer $\mathrm{\kappa B}$ sequence (GGGACTTTCC) of the immunoglobulin $\kappa$ light chain gene. Under physiological conditions, NF- $\kappa \mathrm{B}$ is located in the cytoplasm, where the p65 subunit binds to the $\kappa \mathrm{B}$ inhibitor protein (I $\mathrm{I} B$ ) monomer, covering the nuclear localization signal of the p50 protein; 
Table II. Comparison of serum lipid levels in apolipoprotein E-/- mice from the various groups.

\begin{tabular}{llllcc}
\hline Group & $\mathrm{n}$ & TC $(\mathrm{mmol} / \mathrm{l})$ & $\mathrm{TG}(\mathrm{mmol} / \mathrm{l})$ & LDL-C $(\mathrm{mmol} / \mathrm{l})$ & $\mathrm{HDL}-\mathrm{C}(\mathrm{mmol} / \mathrm{l})$ \\
\hline Normal control & 8 & $11.87 \pm 1.78$ & $1.26 \pm 0.19$ & $5.09 \pm 1.09$ & $2.03 \pm 0.86$ \\
Model & 8 & $36.66 \pm 1.91^{\mathrm{a}}$ & $1.64 \pm 0.19^{\mathrm{b}}$ & $33.08 \pm 1.61^{\mathrm{a}}$ & $7.64 \pm 0.98^{\mathrm{a}}$ \\
Tianxiangdan & 8 & $32.04 \pm 0.99^{\mathrm{c}}$ & $1.46 \pm 0.16$ & $18.76 \pm 1.44^{\mathrm{c}}$ & $8.39 \pm 1.13$ \\
Atorvastatin & 8 & $31.67 \pm 2.19^{\mathrm{c}}$ & $1.60 \pm 0.15$ & $19.12 \pm 2.39^{\mathrm{c}}$ & $8.54 \pm 1.35$ \\
\hline
\end{tabular}

Data are presented as the mean \pm standard deviation. ${ }^{\mathrm{a}} \mathrm{P}<0.01,{ }^{\mathrm{b}} \mathrm{P}<0.05$, compared with the normal control group; ${ }^{\mathrm{c}} \mathrm{P}<0.01$, compared with the model group. TC, total cholesterol; TG, triglyceride; LDL-C, low-density lipoprotein cholesterol; HDL-C, high-density lipoprotein cholesterol.

Table III. Serum levels of IL- $1 \beta$ and TNF- $\alpha$ in apolipoprotein E-/- mice.

\begin{tabular}{llcc}
\hline Group & $\mathrm{n}$ & $\mathrm{IL}-1 \beta(\mathrm{pg} / \mathrm{ml})$ & $\mathrm{TNF}-\alpha(\mathrm{pg} / \mathrm{ml})$ \\
\hline Normal control & 8 & $12.33 \pm 2.09$ & $8.26 \pm 5.04$ \\
Model & 8 & $35.39 \pm 1.56^{\mathrm{a}}$ & $61.74 \pm 8.06^{\mathrm{a}}$ \\
Tianxiangdan & 8 & $25.16 \pm 1.17^{\mathrm{b}}$ & $26.30 \pm 5.08^{\mathrm{b}}$ \\
Atorvastatin & 8 & $24.60 \pm 1.29^{\mathrm{b}}$ & $24.24 \pm 6.74^{\mathrm{b}}$ \\
\hline
\end{tabular}

Data are presented as the mean \pm standard deviation. ${ }^{\mathrm{a}} \mathrm{P}<0.01$, compared with the normal control group; ${ }^{\mathrm{b}}<0.01$, compared with the model group. IL, interleukin; TNF, tumor necrosis factor.

therefore, the NF- $\kappa \mathrm{B}$ complex is in the inactive state, which cannot enter the nucleus and serve a regulatory role (20). When the body is exposed to external stimuli, I $\kappa \mathrm{B}$ undergoes phosphorylation, dissociates from the NF- $\kappa \mathrm{B}$ dimers, thus exposing the nuclear localization signal of the p50 protein, resulting in $N F-\kappa B$ activation and nuclear translocation. Subsequently, $\mathrm{NF}-\kappa \mathrm{B}$ binds with the specific binding site on DNA strands and initiates gene transcription and protein expression; therefore, $\mathrm{NF}-\kappa \mathrm{B}$ serves an important role in regulation of the immune response, inflammatory reaction and cell growth (21). Numerous studies have revealed that activated NF- $\kappa \mathrm{B}$ can be found in atherosclerotic sites and plaques, whereas in normal blood vessels, little or no expression of $N F-\kappa B$ is detected $(22,23)$. Once activated, $N F-\kappa B$ is involved in regulation of the activation and transcription of AS-associated genes, promoting the occurrence and development of AS, thus suggesting that activation of the $N F-\kappa B$ signaling pathway is closely associated with the occurrence and development of AS (24-27). In AS pathology, $N F-\kappa B$ regulates the expression of numerous genes, including cytokines (TNF- $\alpha$, IL-1 and IL-6), monocyte chemoattractant proteins and adhesion molecules, and it participates in inflammation, which can lead to the formation of atherosclerotic plaques, and can result in plaque instability and rupture $(28,29)$. It is well known that the proinflammatory cytokines IL-1 and TNF- $\alpha$ are regulated by $\mathrm{NF}-\kappa \mathrm{B}$; at least one $\kappa \mathrm{B}$ sequence is present in their promoters and enhancers. When $N F-\kappa B$ is activated it binds to the $\kappa \mathrm{B}$ binding site, resulting in activation of IL-1 and TNF- $\alpha$ genes; therefore, the genetic transcripts of IL-1 and TNF- $\alpha$ are enhanced, and the production and release of IL- 1 and TNF- $\alpha$ is increased. IL-1 and TNF- $\alpha$ serve an important role in the
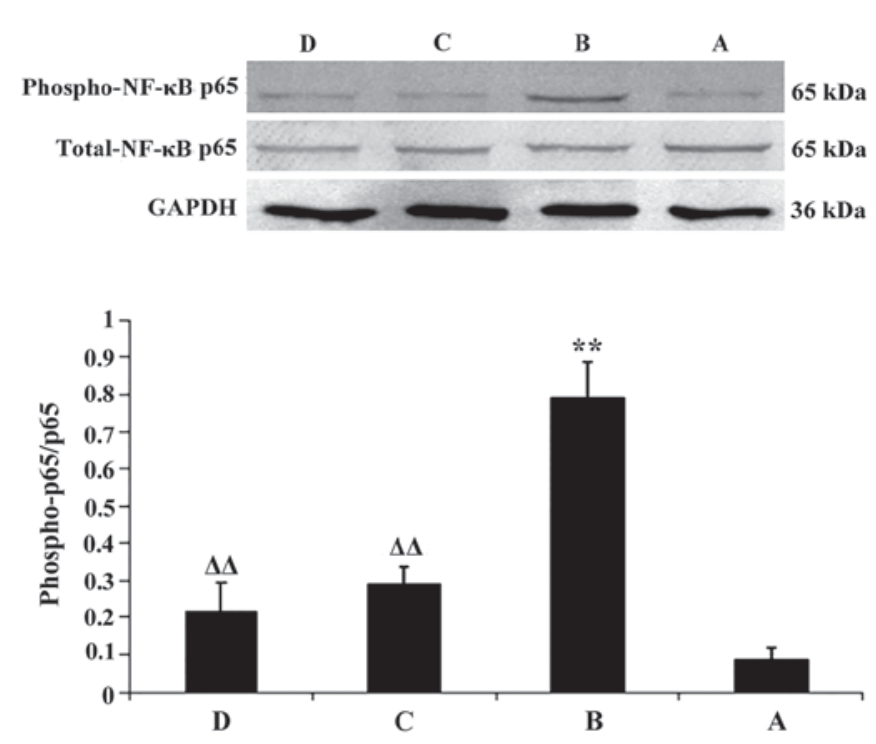

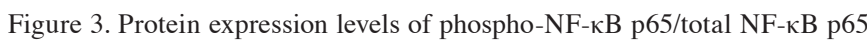
in the aortic tissues of apolipoprotein $\mathrm{E}^{-/}$mice in various groups. Data are expressed as the mean \pm standard deviation of three independent experiments. A, normal control group; B, model group; C, Tianxiangdan group; $\mathrm{D}$, atorvastatin group. ${ }^{* *} \mathrm{P}<0.01$, compared with the normal control group; ${ }^{\Delta \Delta} \mathrm{P}<0.01$, compared with the model group. NF, nuclear factor; phospho, phosphorylated.

inflammatory immune response (30-33), and IL-1 and TNF- $\alpha$ are activators of the NF- $\kappa$ B signaling pathway, which results in further activation of $N F-\kappa B$, whereas activated $N F-\kappa B$ binds to the $\kappa \mathrm{B}$ binding site in the TNF- $\alpha$ and IL-1 gene promoters, resulting in enhancement of the transcription and expression of TNF- $\alpha$ and IL-1; therefore, the inflammatory response is strengthened. During this process, the inflammatory factors TNF- $\alpha$ and IL-1, and associated cytokines, are released from positive and negative feedback loops, and via NF- $\kappa \mathrm{B}$ activation, resulting in the upregulation of cytokines and persistence of inflammation. These findings indicated that TNF- $\alpha$ and IL-1 may participate in the occurrence and development of AS $(34,35)$.

The MAPK signaling pathway is an important pathway that mediates the information transfer between extracellular signals, and intracellular and nuclear signals (36). The MAPK family is predominantly composed of extracellular signal-regulated kinase (ERKI/2), stress-activated protein kinase/c-Jun $\mathrm{N}$-terminal kinase (JNK) and p38 MAPK. Each MAPK is activated by a specific MAPK kinase (MAPKK), which is in turn activated by a MAPKK kinase; through this conservative 

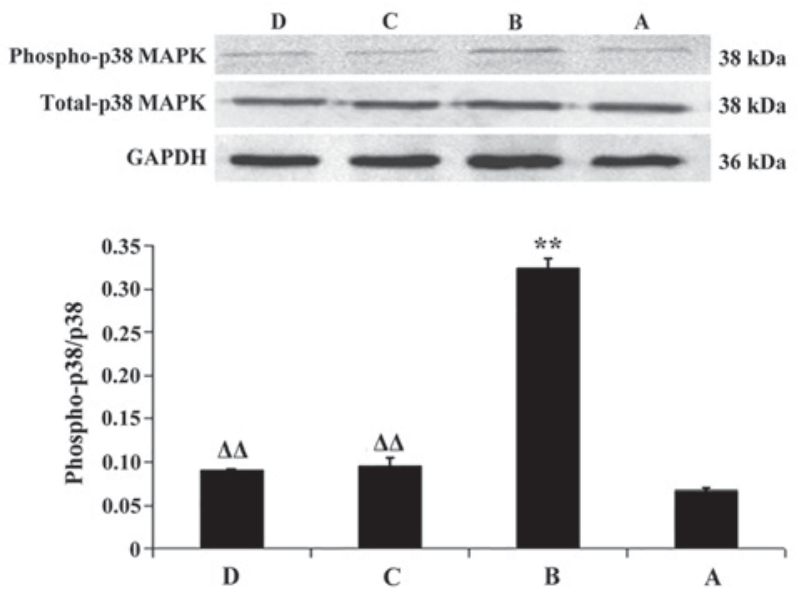

Figure 4. Protein expression levels of phospho-p38 MAPK/total p38 MAPK in the aortic tissues of apolipoprotein $\mathrm{E}^{-/}$mice in various groups. Data are expressed as the mean \pm standard deviation of three independent experiments. A, normal control group; B, model group; C, Tianxiangdan group; $\mathrm{D}$, atorvastatin group. ${ }^{* *} \mathrm{P}<0.01$, compared with the normal contro group; ${ }^{\Delta} \mathrm{P}<0.01$, compared with the model group. MAPK, mitogen-activated protein kinase; phospho, phosphorylated.

tertiary enzymatic cascade, MAPK signaling pathways activate their downstream transcription factors (37). p38 MAPK, which is a member of the MAPK family, is an important intracellular signaling pathway involved in the inflammatory response, which is closely associated with the mechanisms underlying inflammatory regulation and control (38). The p38 MAPK signaling pathway is predominantly involved in cellular inflammation and apoptosis under stress conditions (39), and activation of the p38 MAPK signaling pathway is associated with the release of various inflammatory cytokines. It has previously been reported that specific blocking of the p38 MAPK pathway can reduce inflammation (40). When the body is exposed to long-term inflammation, p38 MAPK and NF- $\mathrm{KB}$ may be activated; and activation of p38 MAPK further activates NF- $\mathrm{\kappa B}$ via phosphorylation, or inflammatory cytokine (TNF- $\alpha$ and IL-1) secretion (41-43). In addition, when $\mathrm{NF}-\mathrm{\kappa B}$ is activated, it may in turn activate the p38 MAPK signaling pathway via its products, including the inflammatory cytokines TNF- $\alpha$ and IL-1. These findings suggested that a complex mutual activating network exists between p38 MAPK and $\mathrm{NF}-\kappa \mathrm{B}$, ultimately resulting in NF- $\mathrm{KB}$ and $\mathrm{p} 38$ MAPK activation, which mediates the inflammatory response and may participate in the formation of AS $(44,45)$.

The incidence of AS is higher in the Xinjiang area compared with in the other provinces of China; this is primarily due to the specific climate, and the lifestyle and dietary habits of the local people. Professor Dongqing An, a doctor whose expertise is in traditional Chinese medicine, initially proposed that the Huizhuo Tanzu type is the main type of AS present in the Xinjiang region of China, due to the specific climate, and the diet and lifestyle characteristics of the local inhabitants (46). Clinical manifestations of this type of AS include: Chest tightness, chest pain, halitosis, nausea and vomiting, belching, abdominal distension, gastric distress, dizziness, drowsiness, poor or smelly stools or constipation, dark tongue, elevated pulse pressure and thick and greasy hair. A series of prescriptions, which are clinically effective for the treatment of Huizhuo Tanzu type AS, have been successfully developed, including Tianxiangdan, which has been clinically applied for the treatment of AS in China for $>30$ years. A previous study used an artificial climate box to simulate the specific climate of the Xinjiang region and fed $\mathrm{ApoE}^{-/}$mice a high-fat diet, resulting in the successful establishment of Huizhuo Tanzu type AS animal model (14). Therefore, the Huizhuo Tanzu type AS model may be used for further experimental studies on the anti-AS mechanism of Tianxiangdan Granule.

In the present study, $\mathrm{ApoE}^{-/}$mice were fed a high-fat diet to simulate the diet characteristics of Xinjiang residents, and to simulate the specific climate and environment of the Xinjiang region the mice were placed in an artificial climate box. Following successful replication of the Huizhuo Tanzu type AS animal model, each group of mice received a different intervention. The aortic PA/LA ratio was significantly higher in the model group compared with in the normal control group, whereas the PA/LA ratio was reduced in the Tianxiangdan and atorvastatin groups compared with in the model group. There was no significant difference in the PA/LA ratio between the Tianxiangdan and atorvastatin groups, thus suggesting that the Tianxiangdan Granule can inhibit the formation of atherosclerotic plaques and may reduce PA. Serum lipid levels were determined by enzymatic colorimetry, and the results indicated that the serum contents of TG, TC, HDL-C and LDL-C were significantly higher in the model group compared with in the normal control group. The increase in HDL-C levels in the model group may be associated with the murine stress response. TC and LDL-C levels in the Tianxiangdan and atorvastatin groups were significantly lower than in the model group; however, there was no significant difference in TC and LDL-C levels between the Tianxiangdan and atorvastatin groups, thus suggesting that Tianxiangdan Granule may regulate blood lipid levels via reducing TC and LDL-C levels. The serum expression levels of IL- $1 \beta$ and TNF- $\alpha$ were determined by ELISA; the results revealed that the expression levels of IL-1 $\beta$ and TNF- $\alpha$ levels were significantly higher in the model group compared with in the normal control group, whereas IL-1 $\beta$ and TNF- $\alpha$ expression was reduced in the Tianxiangdan and atorvastatin groups. These findings suggested that Tianxiangdan Granule may reduce the serum expression levels of IL- $1 \beta$ and TNF- $\alpha$ in an $\mathrm{ApoE}^{-/-}$mouse model of Huizhuo Tanzhu type AS, resulting in inhibition of the inflammatory response. Aortic tissue protein expression levels were detected in the $\mathrm{ApoE}^{-/}$mice by western blotting; the results revealed that the protein expression levels of $\mathrm{p}-\mathrm{NF}-\mathrm{\kappa B}$ p65 and p-p38 MAPK were significantly upregulated in the model group. However, following treatment with Tianxiangdan Granule or atorvastatin, the phosphorylation levels of NF- $\mathrm{KB}$ p65 and p38 MAPK were reduced. However, there was no significant difference in the phosphorylation levels of NF- $\mathrm{KB}$ p65 and p38 MAPK between the Tianxiangdan and atorvastatin groups. Previous studies have aimed to determine the mechanisms underlying the anti-AS effects of traditional Chinese medicine, and have focused on various inflammatory signaling pathways, including p38 MAPK, JNK, ERK1/2 and NF- $\kappa B$. These studies have revealed that Chinese medicine may suppress the inflammatory response via its effects on the phosphorylation levels of $\mathrm{p} 38$ MAPK and NF- $\mathrm{KB}$ p65; this may explain how these medicines exert their anti-AS 
effects (47-54). Since these signaling pathways influence each other, and form complex and changeable networks, the present study only investigated the effects of Tianxiangdan Granule on p38 MAPK and NF- $\mathrm{NB}$ signaling pathways, and aimed to determine whether Tianxiangdan Granule exerts anti-AS effects via related signaling pathways. Our research group aims to conduct further in-depth studies in subsequent research.

In conclusion, the present study indicated that Tianxiangdan Granule is able to reduce AS PA, regulate the level of serum lipids, and inhibit expression of the inflammatory cytokines, IL-1 $\beta$ and TNF- $\alpha$. Therefore, Tianxiangdan Granule may serve an anti-AS role. These functions may be mediated by inhibition of the phosphorylation levels of NF- $\mathrm{NB}$ and $\mathrm{p} 38$ MAPK signaling pathways.

\section{Acknowledgements}

The present study was supported by a grant from the National Nature Science n of China (grant nos. 81160428 and 81360571). The authors would like to thank Mr. Liang Li (Experimental center of the First Affiliated Hospital of Xinjiang Medical University, Urumqi, China) for his technical help in animal experimentation.

\section{References}

1. Lehrke M and Lebherz C: AAV-mediated gene therapy for atherosclerosis. Curr Atheroscler Rep 16: 434, 2014.

2. Sidney S, Rosamond WD, Howard VJ and Luepker RV; National Forum for Heart Disease and Stroke Prevention: The 'heart disease and stroke statistics-2013 update' and the need for a national cardiovascular surveillance system. Circulation 127: 21-23, 2013.

3. Chen WW, Gao RL and Liu LS: The Chinese cardiovascular disease report 2014 Profile. Chin Circulat J: 617-622, 2015.

4. Anogeianaki A, Angelucci D, Cianchetti E, D'Alessandro M, Maccauro G, Saggini A, Salini V, Caraffa A, Tete S, Conti F, et al: Atherosclerosis: A classic inflammatory disease. Int J Immunopathol Pharmacol 24: 817-825, 2011.

5. Charakida M, O'Neil F, Masi S, Papageorgiou N and Tousoulis D: Inflammatory disorders and atherosclerosis: New therapeutic approaches. Curr Pharm Des 17: 4111-4120, 2011.

6. Hansson GK: Inflammation, atherosclerosis, and coronary artery disease. N Engl J Med 352: 1685-1695, 2005.

7. Ross R: Atherosclerosis is an inflammatory disease. Am Heart J 138: S419-S420, 1999.

8. An D, Hu J, Zhao M and Zheng J: Effect of Tianxiangdan on serum vascular endothelial growth factor and correlative factors in coronary heart disease. Chin J Integrat Med Cardio/Cerebrovas Dis 5: 662-664, 2007 (In Chinese).

9. An D, Zhou M, Zhang X and Ling C: Effect of Tianxiangdan on thrombosis and myocardial ultramicrostructure in rat model with myocadial ischemia. J Xinjiang Med Uni 30: 434-437, 2007 (In Chinese).

10. Yin J, Zhu J, Liu Q and An Q: The effect of Tianxiangdan granule on T-SOD, GSH-Px, MDA, LD in serum of angina of coronary heart disease patients. Chin J Inform Trad Chin Med 10: 13-15, 2003 (In Chinese)

11. Wang XY, Jiao YJ and An DQ: Effects of different concentrations of Tianxiangdan on blood lipid and VEGF levels in ApoE (-/-) gene knockout mice with atherosclerosis. J Emer Trad Chin Med 23: 400-403,415S4, 2014 (In Chinese).

12. An DQ: A medicine for treating coronary heart disease and its preparation method, CN200910210063.9. Filed Nov 4, 2009; issued May 11, 2011.

13. Gao Z, Ablimiti A and Wufuer H: Thinking about the establishment of animal model of cold dryness syndrome in Northwest China. Chin J Inf Tradit Chin Med 17: 6-7, 2010 (In Chinese).

14. Niyazi G, An DQ and Li M: Study on Establishing Animal Model of Huizhuo Tanzu Type Atherosclerosis. Chin J Exp Tradit Med Form 19: 265-269, 2013 (In Chinese).
15. Xu SY, Bian RL and Chen X: The Experimental Method of Pharmacology. Third edition. Beijing: People's Med Publishing House, 2013 (In Chinese).

16. Lucas AR, Korol R and Pepine CJ: Inflammation in atherosclerosis: Some thoughts about acute coronary syndromes. Circulation 113: e728-e732, 2006.

17. Li YJ, Yang Q and Zhu XX: TCM anti-inflammation: An effective approach for treating atherosclerosis. Mod Tradit Chin Med Mater Med-World Sci Technol 9: 22-28, 2007 (In Chinese).

18. Daviglus ML, Talavera GA, Avilés-Santa ML, Allison M, Cai J, Criqui MH, Gellman M, Giachello AL, Gouskova N, Kaplan RC, et al: Prevalence of major cardiovascular risk factors and cardiovascular diseases among hispanic/latino individuals of diverse backgrounds in the United States. JAMA 308: 1775-1784, 2012.

19. Sen R and Baltimore D: Multiple unclear factors interact with the immunoglobulin enhancer sequences. Cell 46: 705-716, 1986.

20. Gordon JW, Shaw JA and Kirshenbaum LA: Multiple facets

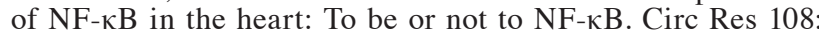
1122-1132, 2011.

21. Ghosh S, May M J and Kopp EB: NF-kappa B and Rel proteins: Evolutionarily conserved mediators of immune responses. Annu Rev Immunol 16: 225-260, 1998

22. Misra A, Haudek SB, Knuefermann P, Vallejo JG, Chen ZJ, Michael LH, Sivasubramanian N, Olson EN, Entman ML and Mann DL: Nuclear factor-kappaB protects the adult cardiac myocyte against ischemia-induced apoptosis in a murine model of acute myocardial infarction. Circulation 108: 3075-3078, 2003.

23. Morita M, Yano S, Yamaguchi T and Sugimoto T: Advanced glycation end products-induced reactive oxygen species generation is partly through NF-kappa B activation in human aortic endothelial cells. J Diabetes Complications 27: 11-15, 2013.

24. Lawrence T, Gilroy DW, Colwille Nash PR and Willoughby DA: Possible new role for NF-kappa B in the resolution of inflammation. Nat Med 7: 1291-1297, 2001.

25. Freund C, Schmidt-Ullrich R, Baurand A, Dunger S, Schneider W, Loser P, El-Jamali A, Dietz R, Scheidereit C and Bergmann MW: Requirement of nuclear factor-kappaB in angiotensin II- and isoproterenol-induced cardiac hypertrophy in vivo. Circulation 111: 2319-2325, 2005.

26. Zelarayan L, Renger A, Noack C, Zafiriou MP, Gehrke C, van der Nagel R, Dietz R, de Windt L and Bergmann MW: NF-kappaB activation is required for adaptive cardiac hypertrophy. Cardiovasc Res 84: 416-424, 2009.

27. Liuzzo G, Santamaria M, Biasucci LM, Narducci M, Colafrancesco V, Porto A, Brugaletta S, Pinnelli M, Rizzello V, Maseri A and Crea F: Persistent activation of nuclear factor kappa-B signaling pathway in patients with unstable angina and elevated levels of C-reactive protein evidence for a direct proinflammatory effect of azide and lipopolysaccharide-free C-reactive protein on human monocytes via nuclear factor kappa-B activation. J Am Coll Cardiol 49: 185-194, 2007.

28. Wu XL, Zheng B, Jin LS, Zhang RN, He M, Yang Z and Wen JK: Chinese medicine Tongxinluo reduces atherosclerotic lesion by attenuating oxidative stress and inflammation in microvascular endothelial cells. Int J Clin Exp Pathol 8: 6323-6333, 2015.

29. Kang Q,Liu W,LiuH andZhou M: Effect of compound chuanxiong capsule on inflammatory reaction and PI3K/Akt/NF- $\kappa \mathrm{B}$ signaling pathway in atherosclerosis. Evid Based Complement Alternat Med 2015: 584596, 2015.

30. Latkovslds G, Licis N and Kalnms U: C-reactive protein levels and common polymorphisms of the interleukin-1 gene cluster and interleukin-6 gene in patients with coronary heart disease. Eur J Immunogenet 31: 207-213, 2004.

31. Zhu T, Zhang L, Ling S, Duan J, Qian F, Li Y and Xu JW: Scropolioside B inhibits IL-1 $\beta$ and cytokines expression through $\mathrm{NF}-\mathrm{\kappa B}$ and inflammasome NLRP3 pathways. Mediators Inflamm 2014: 819053, 2014.

32. Popa C, Netea MG, van-Riel PL, van der Meer JW and Stalenhoef AF: The role of TNF-alpha in chronic inflammatory conditions, intermediary metabolism, and cardiovascular risk. J Lipid Res 48: 751-762, 2007.

33. Zhang H, Park Y, Wu J, Chen Xp, Lee S, Yang J, Dellsperger KC and Zhang C: Role of TNF-alpha in vascular dysfunction. Clin Sci (Lond) 116: 219-230, 2009.

34. Novitskiy G, Ravi R, Potter JJ, Rennie-Tankersley L, Wang L and Mezey E: Effects of acetaldehyde and TNF alpha on the inhibitory kappa B-alpha protein and nuclear factor kappa B activation in hepatic stellate cells. Alcohol Alcohol 40: 96-101, 2005. 
35. Morello S, Ito K, Yamamura S, Lee KY, Jazrawi E, Desouza P, Barnes P, Cicala C and Adcock IM: IL-1beta and TNF-alpha regulation of the adenosine receptor (A2A) expression: Differential requirement for NF-kappa $\mathrm{B}$ binding to the proximal promoter. J Immunol 177: 7173-7183, 2006.

36. Schramek H: MAP kinases: From intracellular signals to physiology and disease. News Physiol Sci 17: 62-67, 2002.

37. Garrington TP and Johnson GL: Organization and regulation of mitogen-activated protein kinase signaling pathways. Curr Opin Cell Biol 11: 211-218, 1999.

38. Dunn KL, Espino PS, Drobic B, He S and Davie JR: The Ras-MAPK signal transduction pathway, cancer and chromatin remodeling. Biochem Cell Biol 83: 1-14, 2005.

39. Ju H, Behm DJ, Nerurkar S, Eybye ME, Haimbach RE, Olzinski AR, Douglas SA and Willette RN: p38 MAPK inhibitors ameliorate target organ damage in hypertension: Part1. p38 MAPK-dependent endothelial dysfunction and hypertension. J Pharmacol Exp Ther 307: 932-938, 2003.

40. Goldstein DM and Gabriel T: Pathway to the clinic: Inhibition of P38 MAP kinase. A review of ten chemotypes selected for development. Curr Top Med Chem 5: 1017-1029, 2005.

41. He X, Shu J, Xu L, Lu C and Lu A: Inhibitory effect of astragalus polysaccharides on lipopolysaccharide-induced TNF-a and IL-1 $\beta$ production in THP-1 cells. Molecules 17: 3155-3164, 2012.

42. Yang K, Qiu BY, Yan J, Yang YX, Zhang T, Chen X, Zou YP, Gan HT and Huang XL: Blockade of p38 mitogen-activated protein kinase pathway ameliorates delayed gastric emptying in streptozotocin-induced diabetic rats. Int Immunopharmacol 23: 696-700, 2014

43. El Bekay R, Alvarez M, Monteseirín J, Alba G, Chacón P, Vega A, Martin-Nieto J, Jiménez J, Pintado E, Bedoya FJ and Sobrino F: Oxidative stress is a critical mediator of the angiotensin II signal in human neutrophils: Involvement of mitogen-activated protein kinase, calcineurin, and the transcription factor NF-kappaB. Blood 102: 662-671, 2003.

44. Lindroos PM, Rice AB, Wang YZ and Boner JC: Role of nuclear factor-kappaB and mitogen-activated protein kinase signaling pathways in IL-1beta-mediated induction of alpha-PDGF receptor expression in rat pulmonary myofibroblasts. Immunol 161: 3464-8, 1998.

45. Zhang X, Wu M, Jiang H, Hao J, Zhang Q, Zhu Q, Saren G, Zhang Y, Meng X and Yue X: Angiotensin II upregulates endothelial lipase expression via the NF-kappa B and MAPK signaling pathways. PLoS One 9: e107634, 2014.

46. An DQ, Zhao MF, Zheng J, et al: Xinjiang obstruction of dirty phlegm syndrome retraces. Xinjiang $\mathrm{J}$ Tradit Chin Med 25: 1-2, 2007 (In Chinese).
47. Xiao Y, Wang YC, Li LL, Jin YC, Sironi L, Wang Y and Wang Y: Lactones from Ligusticum chuanxiong Hort. reduces atherosclerotic lesions in apoE-deficient mice via inhibiting over expression of NF-kB-dependent adhesion molecules. Fitoterapia 95: 240-246, 2014.

48. Liang CJ, Lee CW, Sung HC, Chen YH, Wang SH, Wu PJ, Chiang YC, Tsai JS, Wu CC, Li CY and Chen YL: Magnolol reduced TNF- $\alpha$-induced vascular cell adhesion molecule- 1 expression in endothelial cells via JNK/p38 and NF- $\kappa \mathrm{B}$ signaling pathways. Am J Chin Med 42: 619-636, 2014.

49. Chen Z, Cai Y, Zhang W, Liu X and Liu S: Astragaloside IV inhibits platelet-derived growth factor-BB-stimulated proliferation and migration of vascular smooth muscle cells via the inhibition of p38 MAPK signaling. Exp Ther Med 8: 1253-1258, 2014

50. Shen DZ, Xin SL, Chen C and Liu T: Effect of atorvastatin on expression of TLR4 and NF- $\mathrm{B}$ p 65 in atherosclerotic rabbits. Asian Pac J Trop Med 6: 493-496, 2013

51. Bao MH, Zhang YW and Zhou HH: Paeonol suppresses oxidized low-density lipoprotein induced endothelial cell apoptosis via activation of LOX-1/p38MAPK/NF- $\kappa$ B pathway. J Ethnopharmacol 146: 543-551, 2013.

52. Liang CJ, Lee CW, Sung HC, Chen YH, Wang SH, Wu PJ, Chiang YC, Tsai JS, Wu CC, Li CY and Chen YL: Magnolol reduced TNF- $\alpha$-induced vascular cell adhesion molecule- 1 expression in endothelial cells via JNK/p38 and NF- $\kappa \mathrm{B}$ signaling pathways. Am J Chin Med 42: 619-637, 2014.

53. Haeng Park S, Sung YY, Jin Nho $\mathrm{K}$ and Kyoung Kim $\mathrm{H}$ : Anti-atherosclerotic effects of Polygonum aviculare L. ethanol extract in ApoE knock-out mice fed a Western diet mediated via the MAPK pathway. J Ethnopharmacol 151: 1109-1115, 2014.

54. Chang YL, Chen CL, Kuo CL, Chen BC and You JS: Glycyrrhetinic acid inhibits ICAM-1 expression via blocking JNK and NF-kappaB pathways in TNF-alpha-activated endothelial cells. Acta Pharmacol Sin 31: 546-553, 2010.

(i) $($ This work is licensed under a Creative Commons Attribution-NonCommercial-NoDerivatives 4.0 International (CC BY-NC-ND 4.0) License. 